\title{
Apresentação
}

\section{InSURgência e luta de classes}

Não há outra avaliação possível: uma sociedade dividida em classes é marcada pela luta travada por estas mesmas classes para garantir sua reprodução e fazer valer seu projeto societal. Nada mais pertinente que considerar isto na seara da produção intelectual comprometida com uma destas classes e com suas organizações populares. Daí fazer todo o sentido um dossiê dedicado ao horizonte da luta, no contexto de nosso Instituto de Pesquisa, Direitos e Movimentos Sociais (IPDMS), em um ano tão conturbado - leia-se: marcado pela luta de classes - como o de 2016.

O dossiê que esta edição da InSURgência: revista de direitos e movimentos sociais apresenta tem por título "Direito e marxismo: método, ontologia e práxis" e foi organizado por Ricardo Prestes Pazello (UFPR) e Moisés Alves Soares (UNISOCIESC). Trata-se de abertura para temática tão necessária de ser visualizada, por realizar esforço de estudo rigoroso a respeito da realidade social do direito, em sua essência, apontando para as tarefas político-jurídicas de nosso tempo. $O$ rigor do método materialista-histórico se apresenta como resgate imprescindível, que colabora enormemente para o coletivo de pesquisadoras e pesquisadores que integram o IPDMS. Este método, por seu turno, encaminha para a compreensão do que há de mais essencial quanto ao fenômeno jurídico - portanto, de sua ontologia, que, apesar de histórica, existe sem dúvida alguma. Invariavelmente atrelada às relações sociais do capital, a forma jurídica admite no máximo usos táticos, práxis jurídica insurgente de suporte a movimentos sociais. Entretanto, não há possibilidade de apostas na forma jurídica, horizonte este vedado devido ao atrelamento fundamental que a mesma possui com a circulação de mercadorias. Esperamos, assim, que as contribuições aqui apresentadas - o rigor do método, a compreensão 
da ontologia do direito e a práxis requisitada a partir deste contexto - ressoem e que nosso Instituto tenha, dentro de sua pluralidade, o reconhecimento de que a perspectiva marxista para o direito é um dos pontos nevrálgicos para que a crítica jurídica possa de fato avançar, saindo das encruzilhadas nas quais se meteu.

Para concretizar tais contribuições, o presente dossiê - que tem por capa um cartaz que expressa a luta de um dos mais importantes movimentos populares da atualidade brasileira, o Movimento dos Trabalhadores Sem-Teto (MTST), a partir de sua organização no Paraná - traz doze artigos que atacam os três problemas centrais enfrentados pelo Grupo Temático (GT) Direito e Marxismo do IPDMS, entre 2012 e 2016. O debate a respeito do método traz relevante contribuição do filósofo do direito húngaro, Csaba Varga, assim como textos de Ricardo Prestes Pazello, Jonnas Vasconcelos e Flávio Roberto Batista. A dimensão metódica da discussão carrega consigo, como não poderia ser diferente, as demais questões que o dossiê abriga. A compreensão sobre a ontologia do fenômeno jurídico, especialmente a partir de Pachukanis mas também de Marx ou Lukács, reverbera nos textos de Ana Lia Almeida, Vitor Sartori, Marcel Soares de Souza, Mozart Silvano Pereira e do russo Ivan Ivanovitch Makeev. Uma referência à parte merece ser dada ao texto de Moisés Alves Soares, o qual resgata a figura de Roberto Lyra Filho, que em 2016 tem a coincidente efeméride de seus 90 anos de nascimento e 30 anos de falecimento. O resgate crítico do pensamento de Lyra Filho introduz a dimensão da práxis que a relação entre direito e marxismo induz, o que se observa nos textos de Silvia Alapanian e Luiz Otávio Ribas.

Para além de os artigos do dossiê, a presente edição traz a seção "Em defesa da pesquisa", com textos de temas livres, que traz à tona um artigo inédito de pertinente conteúdo sobre a Constituição de 1988, escrito pelo teórico marxista da dependência, Ruy Mauro Marini. Além disso, uma contribuição de Luisa Maria Nunes de Moura e Silva sobre a metodologia da análise dependentista, bem como o estudo de Karen Daniele de Araújo Pimentel e Letícia Veloso Martineli a respeito de uma comunidade tradicional em espaço urbano. 
Em sintonia com o tema do dossiê, nas demais seções da revista são publicados textos que oportunizam acesso a fontes e reflexões mais livres sobre direito e marxismo. Na seção "Diálogos insurgentes", é Ricardo Antunes o entrevistado, falando sobre a conjuntura política das esquerdas brasileiras, o lugar do direito na pesquisa marxista e a preocupação teórica com o debate ontológico desde o marxismo. Já na seção "Temas geradores", dedicada a verbetes, aparecem reflexões sobre a leitura pachukaniana de Hauriou, da pena do filósofo do direito norueguês-canadense Bjarne Melkevik; a relação entre Lênin e o direito, de Pedro Pompeo Pistelli Ferreira; e o debate sobre a advocacia popular trabalhista, de Guilherme Cavicchioli Uchimura.

Na seção "Práxis de libertação", onde há resgate de documentos históricos dos movimentos sociais, sete preciosas fontes são publicadas. O primeiro dos documentos aqui apresentados é o Projeto da Constituição da República Comunista do Brasil, elaborada na década de 1930 pelo Partido Comunista do Brasil (PCB), nome oficial à época, e que representou, segundo seus críticos e persecutores (dentre os quais a polícia política getulista), a exposição de uma das vertentes mais críticas e à esquerda da organização. De 1966 é o segundo documento, o Programa dos 10 pontos dos Panteras Negras redigido por Huey Newton e Bobby Seale, nos Estados Unidos da América do Norte, por ocasião da fundação do Partido dos Panteras Negras de Autodefesa, uma das organizações negras mais reconhecidas do ocidente, e que teve forte influência marxista-fanoniana. Já o Programa da União pela Liberdade e pelos Direitos do Povo (ULDP), de 1972, representa um manifesto que buscava aglutinar aos guerrilheiros do Araguaia as massas camponesas e tradicionais da região, para fins de auxílio e propaganda à luta armada no contexto da ditadura brasileira, sendo, portanto, um documento representativo de uma organização que pretendeu operar como frente de massas, distinguindo-se do Partido Comunista do Brasil (PCdoB) que efetivamente orientava as ações da guerrilha e que fomentou a ULDP. Também relativo à experiência de luta armada em situação de autoritarismo, o Estatuto das Fuerzas Armadas Revolucionarias de Colombia, Ejército del Pueblo (FARC-EP), de 1978 e atualizado pela terceira vez em 2007, é exemplar no 
que tange à estrutura de regulamentação interna de um grupo revolucionário, o qual, aliás, causa tanta polêmica e que teve tanto destaque no ano de 2016 por conta das tratativas frustradas de um acordo de paz na Colômbia. Dentre os documentos mais recentes, o primeiro é o manifesto $A$ mulher mapuche e seu compromisso com a luta de seu povo, redigido em 2003, pela organização mapuche Meli Wixan Mapu, do Chile, em que a luta das mulheres aparece em destaque, em meio à especificidade da questão cultural e territorial indígena. Por sua vez, a Plataforma Operária e Camponesa da Energia, em 2014, elaborou suas Propostas para um projeto energético popular, que expressa um conjunto de apontamentos práticos de setor significativo das esquerdas marxistas brasileiras, as que apostam em um projeto popular para o Brasil. Por fim, a Declaração final do Encontro Hemisférico Derrota da ALCA, 10 anos depois, assinada em Havana, em 2015, por uma grande variedade de movimentos populares da América Latina, ganha grande atualidade, em tempos de aberta regressão no continente, quanto aos chamados governos progressistas e suas políticas inclusivas, por obra do imperialismo. Assim, os documentos aqui reunidos expressam, em maior ou menor medida, os impactos do debate marxista sobre os movimentos populares e suas concepções de justiça, renovando a interpretação sobre a luta de classes e incorporando nela debates como os de projeto nacional de poder, antirracismo, povo como expressão de classe, autodefesa e auto-organização, feminismo e luta indígena, aliança operário-camponesa e anti-imperialismo.

A revista ainda reserva espaço para textos artísticos, na seção "Poéticas políticas", que neste número conta com expressões lúdicas em quatro áreas distintas: uma tirinha de Laerte, a partir do mote clássico da organização política marxista - "proletários de todo o mundo, uni-vos!"; as artes plásticas de Diego Kern Lopes, representando uma instigante e provocativa perspectiva sobre o antagonismo em desenho materialista-geométrico-político; um poema de Maria Tereza Queiroz Carvalho Carvalho, que enfoca o modo de vida sertanejo; e, por fim, a mostra de fotografias de Giorgia Prates, tematizando, em seis cliques, a disputa de consciências e a busca por transformação no contexto das lutas sociais do povo brasileiro. 
A última seção, "Caderno de retorno", guarda a iniciativa de resenhar recentes publicações do cenário editorial brasileiro, incluindo o clássico livro de Bernard Edelman sobre a legalização da classe operária, comentado por Caio Henrique Amaro; a coletânea organizada por Marcos del Roio, Anderson Deo e Antonio Carlos Mazzeo, sobre Lênin, interpretada por Pedro Pompeo Pistelli Ferreira; a compilação de textos de José Ricardo Menacho, circunscrevendo obra de sensibilidade e conversação, apresentada na resenha de Luciana Stephani Silva locca; e a obra de Franz Hinkelammert, que relaciona e opõe mercado e direitos humanos, resenhada por Luana de Freitas Vignola.

$\mathrm{Na}$ árdua tarefa da disputa das idéias, a partir de uma construção de conhecimento referenciada nas classes populares e trabalhadoras, ainda mais em tempos de avanço neoliberal e desestabilização institucional, como é a pela qual o Brasil passa, uma tentativa, ainda que estruturalmente modesta mas politicamente arrojada, se faz premente e, cremos, que está consubstanciada na presente edição.

\title{
Fora Temer!
}

Alerta! Alerta! Alerta aos fascistas! A América Latina será toda socialista!

\section{Alexandre Bernardino Costa}

\author{
Editor-chefe
}

\section{Assis da Costa Oliveira \\ Diego Augusto Diehl \\ Talita Tatiana Dias Rampin}

Comitê Editorial
Moisés Alves Soares

Ricardo Prestes Pazello

Coordenadores do Dossiê 